\title{
Viewpoints on the Way to a Consensus Session
}

\section{Where does insulin resistance start? The liver}

Gianluca Perseghin, Md

\section{THE CENTRAL ROLE OF THE}

UVER - Insulin resistance and the insulin resistance syndrome refer to a constellation of anthropometric and metabolic features that may be summarized as overweight/obesity, glucose intolerance, dyslipidemia, and hypertension. These anthropometric and metabolic abnormalities are associated with type 2 diabetes, cardiovascular disease, polycystic ovary syndrome, and nonalcoholic fatty liver disease. The liver plays a central role in the regulation of whole-body glucose, fatty acid, and amino acid metabolism. It is the main source of endogenous glucose production, it is a major site of fatty acid disposal (esterification and oxidation) and of amino acid metabolism, and it is the primary site of insulin degradation.

\section{Tissue-specific insulin receptor knockout mice}

Studies using tissue-specific insulin receptor knockout have demonstrated that mice lacking the muscle insulin receptor alone (MIRKO) are characterized by reduced insulin-stimulated muscle glucose uptake, but total-body glucose homeostasis remained normal (1). Adipose tissue insulin receptor knockout mice (FIRKO) had impaired adipose tissue glucose uptake but were protected against obesity, glucose intolerance, and dyslipidemia and manifested a prolonged lifespan (1). In contrast, knockout of the insulin receptor in the liver resulted in both fasting and postprandial hyperglycemia and the subsequent development of peripheral (muscle) insulin resistance. Collectively, these observations support the view that hepatic insulin resistance is the primary event and leads to the subsequent development of peripheral (muscle and adipose) tissue insulin resistance.

\section{The model of nonalcoholic fatty liver disease}

Nonalcoholic fatty liver disease (NAFLD) is part of the broad spectrum of nonalcoholic fatty liver diseases, which also includes steatosis. The distinction between fatty liver and steatohepatitis only can be made by examination of liver histology, which allows the assessment of inflammatory infiltrate, cellular degeneration, and necrosis and fibrosis, and cannot be made on the basis of clinical or laboratory parameters. Despite the weak correlation between liver function tests and the severity of liver disease, epidemiological studies have shown that transaminases, and, in particular, elevated alanine aminotransferase (ALT), even if in the normal range, predict new-onset type 2 diabetes independent of classic risk factors, metabolic syndrome, and C-reactive protein (2). The authors postulated that elevated intrahepatic fat (IHF) content played a central role in liver damage and glucose intolerance. Fatty liver is the most common hepatic disorder characterized by triglyceride accumulation within hepatocytes. Although simple fatty liver is thought to be a benign condition, it is characterized by multiple metabolic abnormalities in organs and tissues that are responsive to insulin. Impaired insulinmediated inhibition of hepatic glucose production $(3,4)$, reduced insulinstimulated glucose uptake in skeletal muscle $(3,5,6)$, and decreased inhibition of lipolysis by insulin $(3,6)$ has been doc-

From the Department of Sport, Nutrition and Health, Università degli Studi di Milano, and Internal Medicine San Raphael Scientific Institute, Milan, Italy.

Corresponding author: Gianluca Perseghin, perseghin.gianluca@hsr.it.

The publication of this supplement was made possible in part by unrestricted educational grants from Eli Lilly, Ethicon Endo-Surgery, Generex Biotechnology, Hoffmann-La Roche, Johnson \& Johnson, LifeScan, Medtronic, MSD, Novo Nordisk, Pfizer, sanofi-aventis, and WorldWIDE.

DOI: $10.2337 / \mathrm{dc0}$-S303

(C) 2009 by the American Diabetes Association. Readers may use this article as long as the work is properly cited, the use is educational and not for profit, and the work is not altered. See http://creativecommons. org/licenses/by-nc-nd/3.0/ for details. umented in patients with fatty liver disease. Whether the accumulation of fat in the liver is the primary event leading to hepatic and subsequently peripheral (muscle and adipose tissue) insulin resistance is not clear because of the lack of longitudinal data. In support of primacy of the liver, treatment of type 2 diabetic patients with a hypocaloric very-low-fat diet resulted in an $81 \%$ reduction in IHF content in association with reductions in both basal and insulin-suppressed hepatic glucose production and a decrease in FPG concentration (7). However, there was no significant improvement in insulin-stimulated peripheral glucose disposal (7). Also, in insulin-treated type 2 diabetic patients, the IHF content was closely correlated with the insulin dose and the sensitivity of endogenous (hepatic) glucose production to insulin and best explained the interindividual variation in insulin requirements (8). Moreover, when the relationship between peripheral glucose metabolism and fatty liver were explored in healthy nondiabetic humans, the correlation between the IHF content and peripheral insulin resistance was much stronger than the correlation with intramyocellular lipid content, visceral fat content, or subcutaneous fat content (9). Stefan et al. (10) recently reported that in the model of the metabolically fit, but obese individuals, preserved insulin sensitivity was more strongly associated with lower IHF content than with other parameters of body adiposity, including intramyocellular lipid content, concluding that ectopic fat in the liver may be more important than visceral fat in the determination of such a beneficial phenotype in obesity. Similar conclusions were also reported in individuals with overt type 2 diabetes (11). In the same line of evidence, we observed that in obese adolescents with fatty liver, there was a greater severity of whole-body insulin resistance compared with that of BMI-matched insulin-resistant obese adolescents with normal IHF content (12).

Finally, the lack of adipose tissue in the congenital lipodystrophy is characterized by extreme insulin resistance associated 
with massive hepatic fat accumulation; intervention with subcutaneous leptin administration in these patients improved whole-body insulin sensitivity mainly due to the mobilization of the excessive fatty liver content (13)

These findings in humans suggest that IHF content has an important systemic consequence to adversely affect insulin sensitivity. The above-described observations in humans are consistent with studies in animal models. When an isocaloric moderate-fat diet was given to dogs, a modest degree of peripheral insulin resistance was triggered; meanwhile, a complete inability of insulin to suppress hepatic glucose production during the clamp developed (14). In rodents, increasing or decreasing IHF content had the opposite effect on muscle insulin sensitivity, suggesting that fat accumulation in the liver may be the primary event leading to peripheral insulin resistance (15). When liver-specific enhancement of fatty acid oxidation was implemented in rats fed a high-fat diet, insulin-stimulated peripheral glucose uptake was enhanced even though intramyocellular lipid content actually increased in some muscle types. More recently, selective hepatic overexpression of glycerol-sn-3-phosphate acyltransferase 1 in rats caused hepatic steatosis and hepatic insulin resistance in the absence of obesity and, surprisingly, triglycerides accumulated in the gastrocnemius muscle in concert with development of insulin resistance in that tissue (16). It has been proposed that the liver might release a humoral factor that sensitizes skeletal muscle to insulin (17), and this suggestive hypothesis is supported by the observation that liver extracts enhanced glucose uptake in the isolated rat hindquarter (18). According to this scenario, peripheral insulin resistance may develop as the result of intrahepatic fat accumulation, resulting in the lower release of these humoral factors that impair insulin sensitivity in peripheral (muscle) tissues. Alternatively, it is possible that fatty liver might interfere with insulin degradation (19); the resultant hyperinsulinemia may potentially be able to impair insulin action in peripheral (muscle and adipose) tissues, as shown in benign insulinomainduced hyperinsulinemia (20). This hyperinsulinemia-induced mechanism may be justified also based on the finding of the reverse experiment: when the prolonged infusion of octreotide was administered to extremely insulin-resistant cirrhotic individuals, the correction of hy- perinsulinemia was paralleled by the restoration of normal insulin sensitivity (21).

\section{The liver in the phenotype of the insulin resistance syndrome} Proinflammatory features. NAFLD is considered the hepatic equivalent of the metabolic syndrome $(3,22)$. This is not surprising since NAFLD is closely associated with obesity, diabetes, dyslipidemia, and insulin resistance (the main features of the metabolic syndrome). Recently, it has been reported that excessive accumulation of fat in the liver rather than in the muscle is associated with features of the metabolic syndrome (23). Liver fat was shown to be fivefold higher in individuals with the metabolic syndrome than in those without the metabolic syndrome, and this finding was independent of obesity (23). No differences in intramyocellular lipid content was observed between subjects with and without the metabolic syndrome. Another feature common to both NAFLD and the metabolic syndrome is the presence of a low-grade inflammatory state in adipose tissue and in the liver. The potential link between inflammation and the metabolic syndrome may well be the increased amount of circulating and intracellular fatty acids concentration that are associated with an increase in the intranuclear and total cellular nuclear factor (NF)-кB (24). Of note, liver biopsy of individuals with fatty infiltration were characterized by increased expression of genes involved in monocyte/macrophage recruitment and inflammation, and this was proportional to the severity of IHF accumulation (25). An attractive hypothesis to account, not only for the metabolic but also for the proinflammatory effects of fatty acids in the liver, is that increased concentrations of intracellular fatty acid metabolites (diacylglycerol, fatty acyl CoAs, etc.) activate ІкB kinase (IKK) $-\beta$ and NF-кB (26). Chronic inflammation of the liver secondary to triglyceride infiltration could thereby increase the production of factors that cause systemic insulin resistance. Results in animal models also support this hypothesis. Transgenic activation of the inflammatory mediators IKK- $\beta$ and $\mathrm{NF}-\kappa \mathrm{B}$ in the liver induce systemic insulin resistance, increase circulating levels of interleukin (IL)-6, and upregulate IL-6 target genes in peripheral tissues, including muscle (27). Conversely, administration of antibodies to neutralize circulating IL-6 normalized IL-6 target gene expression and corrected the insulin resistance.
Proatherosclerotic features. Subjects with features of the metabolic syndrome are at risk of developing cardiovascular disease and coronary heart disease (28), and recent evidence suggests that individuals with NAFLD also are at high risk for coronary heart disease. In a prospective study, the 14-year risk of mortality from cardiovascular causes was doubled in patients with biopsy-proven NAFLD compared with a reference population (29). In the Hoorn Study, elevated ALT at baseline increased the 10-year risk of coronary heart disease events, even after adjustment for the components of the metabolic syndrome (30). Cardiovascular risk factors tend to cluster in patients with NAFLD, who exhibit more advanced atherosclerosis than control subjects (31). Recently, we reported that cardiac metabolic remodeling in young men with fatty liver is an early event and occurs before the development of diastolic dysfunction and is independent of known risk factors for cardiovascular disease (age, obesity, hypertension, diabetes, exercise habits) (32). This finding was associated with alteration of surrogate markers of endothelial dysfunction as previously detected (33). Finally, it has been demonstrated that $100 \%$ of mice with selective liver knockout of the insulin receptor gene (LIRKO)—a pure hepatic insulin resistance-develop the metabolic syndrome with severe dyslipidemia and atherosclerosis within 12 weeks after being placed on an atherogenic diet. None of the control mice developed the metabolic syndrome or atherosclerosis (34).

\section{The model of liver cirrhosis}

Patients with liver cirrhosis are characterized by impaired glucose metabolism (35); $60-80 \%$ are glucose intolerant and $10-15 \%$ develop overt diabetes (36-38). The development of diabetes in patients with liver cirrhosis occurs relatively rapidly; over a period of 5 years, $~ 15-20 \%$ of cirrhotic patients develop frank hyperglycemia (39). Diabetes complicating liver cirrhosis, known as hepatogenous diabetes, and the common form of type 2 diabetes are the result of a marked reduction in insulin action and a $\beta$-cell secretory defect that is not able to compensate for the severity of insulin resistance (40). Peripheral insulin resistance plays a major role in its pathogenesis $(41,42)$. The peripheral insulin resistance in these patients has been assessed with positron emission tomography of the skeletal muscle and has been shown to be associated 
with both impaired glucose transport and glycogen synthesis (43). The important role of peripheral insulin resistance in the glucose tolerance of cirrhosis is highlighted by the observation that liver transplantation, when the dosage of immunosuppressive agents is reduced and corticosteroids withdrawn, is able to restore normal insulin sensitivity not only in the liver but also at the level of the skeletal muscle and adipose tissue (44) and normalizes glucose tolerance in most patients with diabetes (40).

CONCLUSIONS - In support of the supremacy of the role of the liver in the onset of insulin resistance and insulin resistance syndrome, we state the following: 1) NAFLD is the hepatic equivalent of the metabolic syndrome. 2) Even though there are no longitudinal data showing that the development of NAFLD is primary and precedes the onset of wholebody insulin resistance, it is plausible, based on animal studies, that the development of peripheral insulin resistance and proinflammatory state is secondary to hepatic fat infiltration and hepatic insulin resistance. 3) Models in which hepatic dysfunction is known to be the primary disturbance provide strong support that insulin resistance in peripheral tissues develops secondary to the liver disease; this is manifested in humans in patients with hepatic cirrhosis.

A final consideration is that insulin resistance is often defined based on measurements of glucose metabolism, but insulin also regulates the anabolism and storage of fat, protein synthesis, and nonmetabolic process such as cell growth and differentiation. In the insulin resistance syndrome, it is important to emphasize that not all insulin-dependent processes and tissues are equally resistant to insulin. Metabolic pathways at the liver site are a good example of this behavior. Accili and coworkers (45) proposed that, when insulin signaling in hepatocytes is impaired, the transcription factor forkhead box $\mathrm{Ol}$ (FoxO1) may play a pivotal role in sustaining this mixed state of resistance versus sensitivity to insulin. This heterogeneous phenotype (insulin resistance with respect to glucose metabolism and insulin sensitivity with respect to lipogenesis) seems to be a typical behavior of the liver able to explain simultaneously all the metabolic features (dysglycemia and dyslipidemia) of the insulin resistance syndrome.
Acknowledgments - The writing of this article was supported by a grant from the European Federation for the Study of Diabetes and by European Community's Framework Programme 6, Estrogen and Women Aging (LSHM-CT-2005-518245).

No potential conflicts of interest relevant to this article were reported

\section{References}

1. Biddinger SB, Kahn CR. From mice to men: insights into the insulin resistance syndromes. Annu Rev Physiol 2006;68: 123-158

2. Sattar N, Scherbakova O, Ford I, O'Reilly D St J, Stanley A, Forrest E, MacFarlane PW, Packard CJ, Cobbe SM, Shepherd J. Elevated alanine aminotransferase predicts new-onset type 2 diabetes independently of classical risk factors, metabolic syndrome, and C-reactive protein in the West of Scotland Coronary Prevention Study. Diabetes 2004;53:2855-2860

3. Marchesini G, Brizi M, Bianchi G, Tomassetti S, Bugianesi E, Lenzi M, McCullough AJ, Natale S, Forlani G, Melchionda N. Nonalcoholic fatty liver disease: a feature of the metabolic syndrome. Diabetes 2001;50:1844-1850

4. Seppala-Lindroos A, Vehkavaara S, Hakkinen AM, Goto T, Westerbacka J, Sovijarvi A, Halavaara J, Yki-Jarvinen H. Fat accumulation in the liver is associated with defects in insulin suppression of glucose production and serum free fatty acids independent of obesity an normal men. J Clin Endocrinol Metab 2002;87:30233028

5. Bugianesi E, Gastaldelli A, Vanni E, Gambino R, Cassader M, Baldi S, Ponti V, Pagano G, Ferrannini E, Pizzetto M. Insulin resistance in non-diabetic patients with non-alcoholic fatty liver disease: sites and mechanisms. Diabetologia 2005;48: $634-642$

6. Pietilainen KH, Rissanen A, Kaprio J, Makimattila S, Hakkinen A-M, Westerbacka J, Sutinen J, Vehkavaara S, YkiJarvinen H. Acquired obesity is associated with increased liver fat, intra-abdominal fat, and insulin resistance in young adult monozygotic twins. Am J Physiol 2005; 288:E768-E774

7. Petersen KF, Dufour S, Befroy D, Lehrke M, Hendler RE, Shulman GI. Reversal of nonalcoholic hepatic steatosis, hepatic insulin resistance, and hyperglycemia by moderate weight reduction in patients with type 2 diabetes. Diabetes 2005;54: 603-608

8. Ryysy L, Häkkinen A-M, Goto T, Vehkavaara S, Westerbacka J, Halavaara J, Yki-Järvinen H. Hepatic fat content and insulin action on free fatty acids and glucose metabolism rather than insulin absorption are associated with insulin requirements during insulin therapy in type 2 diabetic patients. Diabetes 2000; 49:749-758

9. Hwang J-H, Stein DT, Barzilai N, Cui M-H, Tonelli J, Kishore P, Hawkins M. Increased intrahepatic triglyceride is associated with peripheral insulin resistance: in vivo MR imaging and spectroscopy studies. Am J Physiol Endocrinol Metab 2007;293:E1663-E1669

10. Stefan N, Kantartzis K, Machann J, Schick F, Thamer C, Rittig K, Balletshofer B, Machicao F, Fritsche A, Haring H-U. Identification and characterization of metabolically benign obesity in humans. Arch Intern Med 2008;68:1609-1616

11. Gastaldelli A, Cusi K, Pettiti M, Hardies J, Miyazaki Y, Berria R, Buzzigoli E, Sironi AM, Cersosimo E, Ferrannini E, De FRonzo RA. Relationship between hepatic/visceral fat and hepatic insulin resistance in nondiabetic and type 2 diabetic subjects. Gastroenterology 2007;133:496-506

12. Perseghin G, Bonfanti R, Magni S, Lattuada G, De Cobelli F, Canu T, Esposito A, Scifo P, Ntali G, Costantino F, Bosio L, Ragogna F, Del Maschio A, Chiumello G, Luzi L. Insulin resistance and whole body energy homeostasis in obese adolescents with fatty liver disease. Am J Physiol Endocrinol Metab 2006;291: E697-E703

13. Petersen KF, Arioglu Oral E, Dufour S, Befroy D, Ariyan C, Yu C, Cline GW, DePaoli AM, Taylor SI, Gorden P, Shulman GI. Leptin reverses insulin resistance and hepatic steatosis in patients with severe lipodystrophy. J Clin Invest 2002; 109:1345-1350

14. Kim SP, Ellmerer M, Van Citters GW, Bergman RN. Primacy of hepatic insulin resistance in the development of the metabolic syndrome induced by an isocaloric moderate-fat diet in the dog. Diabetes 2003;52:2453-2460

15. An J, Muoio DM, Shiota M, Fujimoto Y, Cline GW, Shulman GI, Koves TR, Stevens R, Millington D, Newgard CB. Hepatic expression of malonyl-CoA decarboxylase reverses muscle, liver, and whole animal insulin resistance. Nat Med 2004; 10:268-274

16. Nagle CA, An J, Shiota M, Torres TP, Cline GW, Liu Z-X, Wang S, Catlin RL, Shulman GI, Newgard CB, Coleman RA. Hepatic overexpression of glycerol-sn-3phosphate acyltransferase 1 in rats causes insulin resistance. J Biol Chem 2007;282: 14807-14815

17. Lautt WW. The HISS story overview: a novel hepatic neurohumoral regulation of peripheral insulin sensitivity in health and diabetes. Can J Physiol Pharmacol 1999;77:553-562

18. Petersen KF, Tygstrup N. A liver factor increasing glucose uptake in rat hindquarters. J Hepatol 1994;20:461-465

19. Kotronen A, Vehkavaara S, Seppälä-Lin- 
droos A, Bergholm R, Yki-Jarvinen H. Effect of liver fat on insulin clearance. Am J Physiol Endocrinol Metab 2007;293: E1709-E1715

20. Battezzati A, Terruzzi I, Perseghin G, Bianchi E, Di Carlo V, Pozza G, Luzi L. Defective insulin action on protein and glucose metabolism during chronic hyperinsulinemia in subjects with benign insulinoma. Diabetes 1995;44:837-844

21. Petrides AS, Stanley T, Matthews DE, Vogt C, Bush AJ, Lambeth A. Insulin resistance in cirrhosis: prolonged reduction of hyperinsulinemia normalizes insulin sensitivity. Hepatology 1998; 28:141-149

22. Marchesini G, Bugianesi E, Forlani G, Cerrelli F, Lenzi M, Manini R, Natale S, Vanni E, Villanova N, Melchionda N, Pizzetto M. Nonalcoholic fatty liver, steatohepatitis, and the metabolic syndrome. Hepatology 2003;37:917-923

23. Kotronen A, Seppälä-Lindroos A, Bergholm R, Yki-Järvinen H. Tissue specificity of insulin resistance in humans: fat in the liver rather than muscle is associated with features of the metabolic syndrome. Diabetologia 2008;51:130-138

24. Tripathy D, Mohanty P, Dhindsa S, Syed T, Ghanim H, Aljada A, Dandona P. Elevation of free fatty acids induces inflammation and impairs vascular reactivity in healthy subjects. Diabetes 2003;52:2882-2887

25. Westerbacka J, Kolak M, Kiviluoto T, Arkkila P, Siren J, Hamsten A, Fisher RM, Yki-Jarvinen H. Genes involved in fatty acid partitioning and binding, lipolysis, monocyte/macrophage recruitment, and inflammation are overexpressed in the human fatty liver of insulin-resistant subjects. Diabetes 2007;56:2759-2765

26. Perseghin G, Petersen KF, Shulman GI. Cellular mechanisms of insulin resistance: potential links with inflammation. Int J Obes 2003;27:S6-S11

27. Cai D, Yuan M, Frantz FD, Melendez PA, Hansen L, Lee J, Shoelson SE. Local and systemic insulin resistance resulting from hepatic activation of IKK-beta and NFkappaB. Nat Med 2005;11:183-190
28. Dekker JM, Girman C, Rhodes T, Nijpels G, Stehouwer CD, BouterLM, Heine RJ. Metabolic syndrome and 10-year cardiovascular disease risk in the Hoorn Study. Circulation 2005;12:666-673

29. Ekstedt M, Franzen LE, Mathiesen UL, Thorelius L, Holmqvist M, Bodemar G, Kechagias S. Long-term follow-up of patients with NAFLD and elevated liver enzymes. Hepatology 2006;44:865-873

30. Schindhelm RK, Dekker JM, Nijpels G, Bouter LM, Stehouwer CD, Heine RJ, Diamant M. Alanine aminotransferase predicts coronary heart disease events: a 10year follow-up of the Hoorn Study. Atherosclerosis 2007;191:391-396

31. Targher G, Bertolini L, Padovani R, Zenari L, Zoppini G, Fralezza G. Relation of nonalcoholic hepatic steatosis to early carotid atherosclerosis in healthy men: role of visceral fat accumulation. Diabetes Care 2004;27:2498-2500

32. Perseghin G, Lattuada G, De Cobelli F, Esposito A, Belloni E, Ntali G, Canu T, Ragogna F, Scifo P, Del Maschio A, Luzi L. Left ventricular energy metabolism is impaired and the intrapericardial and mediastinal fat is increased in young, nondiabetic men with newly found fatty liver. Hepatology 2008;47:51-58

33. Villanova N, Moscatello S, Ramilli S, Bugianesi E, Magalotti D, Vanni E, Zoli M, Marchesini G. Endothelial dysfunction and cardiovascular risk profile in nonalcoholic fatty liver disease. Hepatology 2005; 42:473-480

34. Biddinger SB, Hernandez-Ono A, RaskMadsen A, Haas JT, Aleman J, Suzuki R, Scapa EF, Agarwal C, Carey MC, Stephanopoulos G, Cohen DE, King GL, Ginsberg HN, Kahn CR. Hepatic insulin resistance is sufficient to produce dyslipidemia and susceptibility to atherosclerosis. Cell Metab 2008; 7:125-134

35. Naunyn B. Glykosurie und Diabetes durch experimentelle Insulte und Krankheiten der Leber. In Handbuch Spezielle Pathologie Therapie Band 7, 1. Holder A, Ed. Wien, Austria, 1898, p. 38-49

36. Megyesi C, Samols E, Marks V. Glucose tolerance and diabetes in chronic liver disease. Lancet 1967;2:1051-1056

37. Conn HO, Schreiber W, Elkington SG, Johnson TR. Cirrhosis and diabetes: increased incidence of diabetes in patients with Laennec's cirrhosis. Am J Dig Dis 1969; 14:837-852

38. Conn HO, Schreiber W, Elkington SG. Cirrhosis and diabetes: association of impaired glucose tolerance with portal-systemic shunting in Laennec's cirrhosis. Am J Dig Dis 1971;16:227-239

39. Gentile S, Loguercio C, Marmo R, Carbone L, Del Vecchio-Blanco C. Incidence of altered glucose tolerance in liver cirrhosis. Diabetes Res Clin Pract 1993;22:37-44

40. Perseghin G, Mazzaferro V, Piceni Sereni L, Regalia E, Benedini S, Bazzigaluppi E, Pulvirenti A, Antonio Silva Leão A, Calori G, Romito R, Baratti D, Luzi L. Contribution of reduced insulin sensitivity and secretion to the pathogenesis of hepatogenous diabetes: effect of liver transplantation. Hepatology 2000;31:694-703

41. Petrides AS, De Fronzo RA. Glucose metabolism in cirrhosis: a review with some perspectives for the future. Diabete Metab Rev 1989;5:691-709

42. Petrides AS, Groop LC, Riely CA, De Fronzo RA. Effect of physiologic hyperinsulinemia on glucose and lipid metabolism in cirrhosis. J Clin Invest 1991;88: 561-570

43. Selberg O, Burchert W, vd Hoff J, Meyer GJ, Hundeshagen H, Radoch E, Balks H-J, Muller MJ. Insulin resistance in liver cirrhosis: positron-emission tomography scan analysis of skeletal muscle glucose metabolism. J Clin Invest 1993;91:1897-1902

44. Perseghin G, Regalia E, Battezzati A, Vergani S, Pulvirenti A, Terruzzi I, Baratti D, Bozzetti F, Mazzaferro V, Luzi L. Regulation of glucose homeostasis in humans with a denervated liver. J Clin Invest 1997;100:931-941

45. Matsumoto M, Han S, Kitamura T, Accili D. Dual role of transcription factor FoxO1 in controlling hepatic insulin sensitivity and lipid metabolism. J Clin Invest 2006; 116:2464-2472 